\title{
The Frequency of Fingerprint Type in Parents of Children with Trisomy 21 in Japan
}

\author{
Nagahisa Matsuyama and Yohko Ito \\ Section of Forensic Medicine Department of International Health Development, \\ Division of Public Health, Graduate School, Tokyo Medical and Dental University
}

\begin{abstract}
Analysis of the frequency data of each fingerprint type (arch, ulnar loop, radial loop, and whorl) of the parents of children with Trisomy 21 (Fathers: 71; Mothers: 128) born between 1965 and 1970 obtained from the Tokyo Medical and Dental University Hospital was carried out. Japanese controls were taken from dermatoglyphics data in Japan. We conducted the Friedman test on each type of fingerprint between Japanese controls and parents of Trisomy 21 children.

Results from a statistical analysis based on the above data showed significant differences, more arches $(p<0.0001)$ and fewer whorls $(p<0.05)$ in mothers of children with Trisomy 21. Among fathers of Trisomy 21 children, a significant difference was found in there being fewer whorls $(p<0.05)$ and ulnar loops $(p=0.06)$. Considering the mothers' fingerprints, we suspected that females with a higher frequency of arches and a lower frequency of whorls had a stronger possibility of bearing Trisomy 21 babies. On the other hand, in fathers of Trisomy 21 children, we considered that there would be a possibility of significant differences if cases in the sample were increased. J Physiol Anthropol 25(1): 15-21, $2006 \mathrm{http} / /$ www.jstage.jst.go.jp/browse/jpa2

[DOI: 10.2114/jpa2.25.15]
\end{abstract}

Keywords: Trisomy 21, fingerprint, antholopolgy, embryology

\section{Introduction}

Dermatoglyphics is the study of fingerprints, palmprints and toeprints. Studies of these traits have been advocated by Cummins in the United States (Cummins, 1961). In the history of dermatoglyphics, there are descriptions of fingerprints and palmprints by Grew (Caplan, 1990; Lambourne, 1977) as early as 1684 and by Malpighi in 1686 (Lambourne, 1977). In 1823, for the first time, Purkinje methodically classified fingerprints into 9 types (Caplan, 1990; Cummins and Kennedy, 1991; Lambourne, 1977).

In addition, at the end of the 19th century, Galton reported on the segmentation of dermatoglyphics, comparisons among twins and ethnic groups, and, most importantly, a rule called "proof of no change." This rule states that an individual's dermatoglyphics remain unchanged throughout his/her lifetime (Stigler, 1995). On the basis of these original studies, many researchers have investigated dermatoglyphics in various fields such as forensic medicine, genetics and anthropology. Recently, recognition of irregular fingerprints among patients with certain types of congenital anomalies has drawn attention to the field of medical dermatoglyphics (Schauman and Alter, 1976; Reed, 1981; Shiono, 1986; Honda and Ishida, 1990).

The first report on the irregularity of fingerprints and palmprints in clinical medicine was presented by Cummins (Cummins, 1961). The report concerned the fingerprints of 60 children with Trisomy 21. Later, elucidation of the relationship between Trisomy 21 and irregularities in chromosomes accelerated interest in fingerprints (Blank, 1962; Carr, 1962; Warkany and Soukup, 1963). There are many reports on the relationship between dermatoglyphics and autosome anomalies; among these are Trisomy 21, E-Trisomy, DTrisomy and 5P syndrome. Similar relationships are seen with sex chromosome anomalies, including Klinefelter's and Turner's syndromes (Holt and Lindsten, 1964; Pfeiffer and Kiera, 1968; Cushman and Soltan, 1969; Fujita, 1969; Penrose, 1969; Shiono et al., 1977; Rignell, 1985; Than et al., 1998). Along with reports which examined patients, there has been research on the dermatoglyphics of the parents of patients with autosomal anomalies and sex chromosome anomalies (Holt and Lindsten, 1964; Cushman and Soltan, 1969; Ayme et al., 1975; Schmidt et al., 1981; Loesch, 1981). But, in Japan, no such research has taken place.

Recently, an Israeli anthropologist published a study of dermatoglyphics on the parents of Trisomy 21 patients (Katznelson et al., 1999). This showed a decreased frequency of whorls and arches in parents compared to controls. A constellation of genetic codes are inherited from parents by children, and it is well known that fingerprints are heritable and specific dermatoglyphics are found in congenital anomalies such as Trisomy 21 . We examined the possibility of giving birth to Trisomy 21 children by investigating whether or 
not specific fingerprints appear in parents of Trisomy 21 children.

\section{Material and Methods}

Figure 1 shows the basic fingerprint types. The arch has no triradius, the loop has a single triradius (arrow A) and opens to one side, and the whorl has two or more triradii (arrow B). Loops open toward the ulnar $(\mathrm{U})$ or radial $(\mathrm{R})$ side of the hand and are designated accordingly. Analysis of the fingerprints (arch, ulnar loop, radial loop, and whorl) of parents of children with Trisomy 21 (Fathers: 71; Mothers: 128) was carried out. Controls were taken from the dermatoglyphics data of Kishi and Hirai (1928), Okajima (1969), Matsui (1978), and Shiono (1975) in Japan. Fingerprint data of parents of children with Trisomy 21 born from 1965 to 1970 were obtained from the Tokyo Medical and Dental University Hospital Faculty of Medicine, Tokyo, Japan. The fingerprints and palmprints of children with Trisomy 21 and the palmprints of their parents were not examined. Chromosomal analysis was performed on all children who had the standard Trisomy 21 karyotype (47, $\mathrm{XX},+21$ or $47, \mathrm{XY},+21)$. Prints of the dermal patterns on all their fingers were taken and studied. Statistical analysis was performed using the Friedman test in which we compared the appearance rate of each type of fingerprint between the controls and parents of children with Trisomy 21. The Friedman test is a non-parametric test (distribution-free) used to compare observations repeated on the same subjects. This is also called a non-parametric randomized block analysis of variance.

\section{Results}

Table 1 shows the mothers of children with Trisomy 21 and the female controls. Table 2 shows the fathers of children with Trisomy 21 and the male controls. Table 3 shows the results of a comparison between the controls and parents of children with Trisomy 21 by the Friedman test. With statistical analysis we investigated which types of fingerprints appear more/less frequently in parents of children with Trisomy 21 than controls. The method involved comparing the appearance rate of each type of fingerprint between the controls and parents of children with Trisomy 21 . Results of statistical analysis based on the above data showed significant differences in there being more arches $(p<0.0001)$ and fewer whorls $(p<0.05)$ in mothers of children with Trisomy 21. Based on mothers' fingerprints, we suggest that females with a higher frequency of arches and a lower frequency of whorls had a greater possibility of bearing Trisomy 21 babies.

On the other hand, in fathers of Trisomy 21 children, the data showed significant differences in there being fewer whorls $(p<0.05)$ and ulnar loops $(p=0.06)$. We considered that $p=0.06$ for the ulnar loop was border line and that there would be a possibility of significant differences if the number of cases could be increased.

\section{Discussion}

Basic fingerprints are classified as the arch, ulnar loop, radial loop and whorl (Fig. 1). According to reports by Kishi, Hirai, Okajima, Shiono, and one report by Holt (Okajima, 1975; Shiono, 1983; Holt, 1964), more whorls and fewer ulnar loops are present in Japanese compared to Caucasians. The frequency of each fingerprint type significantly differs depending not only on ethnicity but also by finger and gender (Than et al., 1998). In all groups, males have a greater frequency of whorls and fewer ulnar loops and arches than females.

Although the use of various aspects of dermatoglyphics including fingerprints is not clear in law, the role of inheritance is well recognized. For example, parents with many whorls have a relatively high tendency to produce children with many whorls. Recently, Aihara suggested that inheritance of all types of fingerprints occurs in the same manner (Aihara et al., 1986).

In addition, Hojo reports that changes in dermatoglyphics during inheritance from parent to child can be roughly classified into 4 types (Hojo, 1938). Using this system, fingerprints may be due to genetic similarities between parents and children in many cases. The fingerprints of Trisomy 21 children and their parents have been analyzed by various methods and many articles about fingerprints and inheritance have been published (Ayme et al., 1979; Schmidt et al., 1981; Kaplan et al.,1970; Rodewald et al., 1982; Loesch, 1981; de lzuzquiza Uriszar-Aldaca, 1986).

In Japan, the eruption rate of the ulnar loop is high (84 $94 \%$ ) in the fingerprints of children with Trisomy 21, especially on the index finger (Shiono, 1983). In addition, almost $30 \%$ of Trisomy 21 patients have ulnar loops on all their fingers compared to only $5.7 \%$ in other children (Shiono, 1983). In regard to fingerprint inheritance, parents with many ulnar loops tend to bear babies with many ulnar loops. Accordingly, there is a possibility that parents of children with many ulnar loops may have many ulnar loops. Although fingerprints of parents, brothers or sisters of Trisomy 21 children have been investigated, no clear relationship has been found.

Statistically significant differences were found in there being more arches and fewer whorls in the mothers of Trisomy 21 children, and fewer whorls were seen in the fathers of Trisomy 21 children. Our study of fingerprint formation was from an embryological point of view.

Embryological studies have shown that a ridge appears in the fetus late in the third month or early in the fourth month of life. However, prior to this, a swell called a pad grows on finger heads, palms and plantae (Kimura and Kitazawa, 1986). Pads appear in 6-week-old fetuses and gradually become more conspicuous. In humans the pads begin to disappear after a certain period. Pads on the hands completely disappear in the 12 th fetal week and those on the plantae disappear in the 16th fetal week. The hands and plantae then become flat. On the hand, pad appearance and disappearance always occurs prior to 


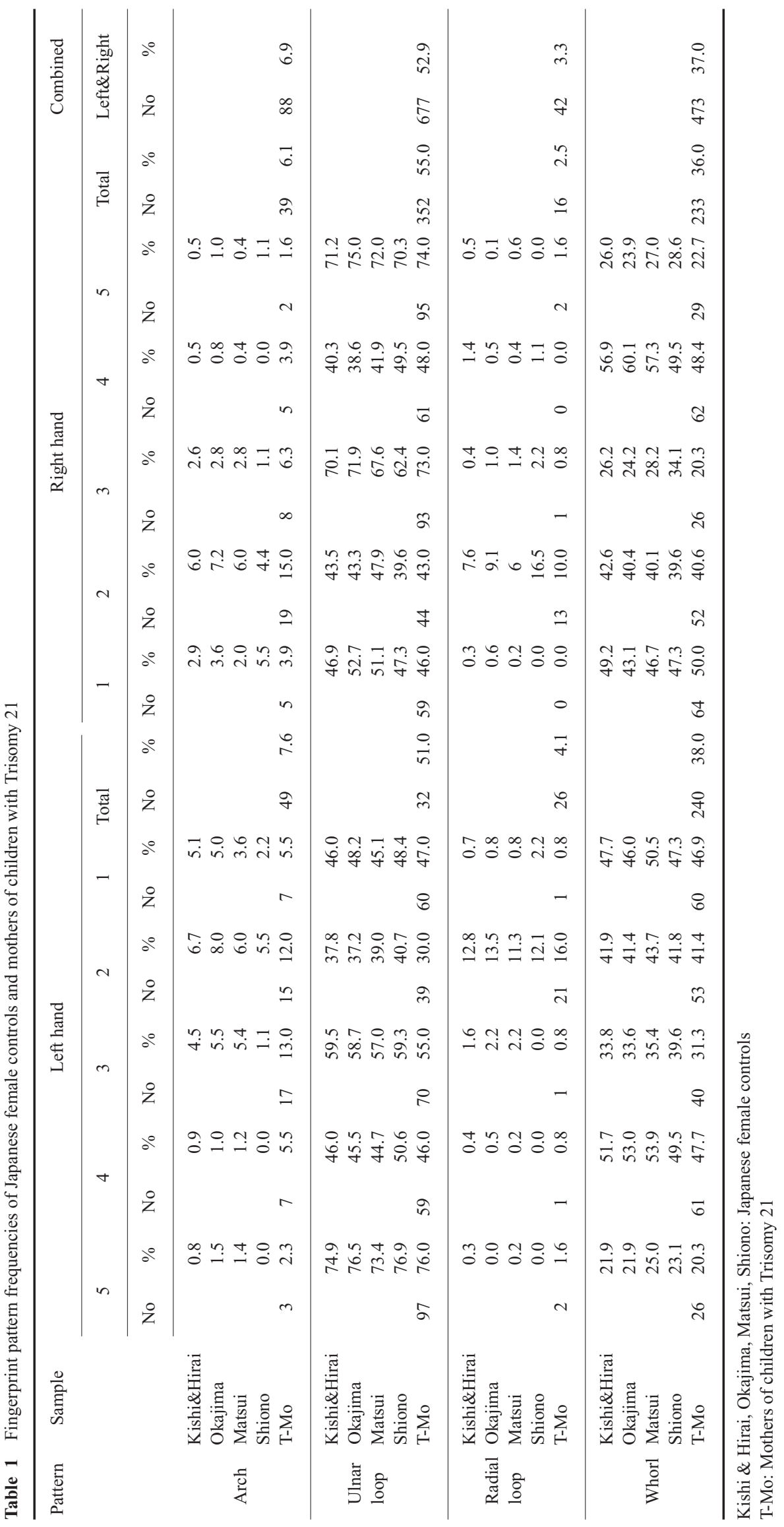




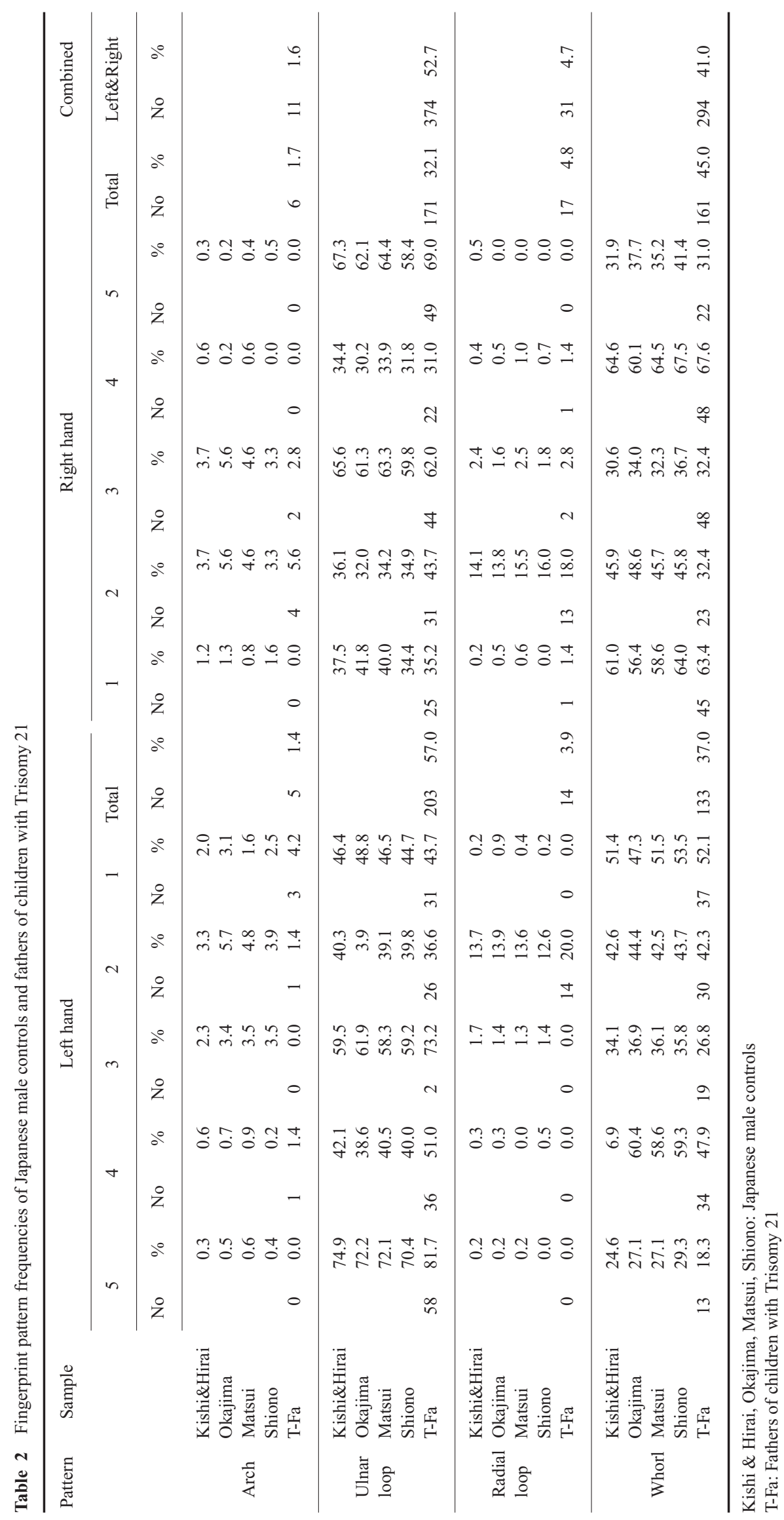


Table 3 Result of a comparison between controls and parents of children with Torisomy 21 by the Friedman test

\begin{tabular}{lllllll}
\hline & \multicolumn{2}{c}{ Female } & & & Male \\
\hline Fingerprint pattern & Compared sample & $p$ value & Fingerprint pattern & Compared sample & $p$ value \\
\hline Arch & Controls vs T-Mo & $p<0.0001$ & Arch & Controls vs T-Fa & $p=0.19$ \\
\hline Radial loop & Controls vs T-Mo & $p=0.83$ & Radial loop & Controls vs T-Fa & $p=0.83$ \\
\hline Ulnar loop & Controls vs T-Mo & $p=0.17$ & Ulnar loop & Controls vs T-Fa & $p=0.06$ \\
\hline Whorl & Controls vs T-Mo & $p=0.03$ & Whorl & Controls vs T-Fa & $p=0.03$ \\
\hline
\end{tabular}

T-Mo: Mothers of children with Trisomy21

T-Fa: Fathers of children with Trisomy 21

\section{Arch Loop Whorl}

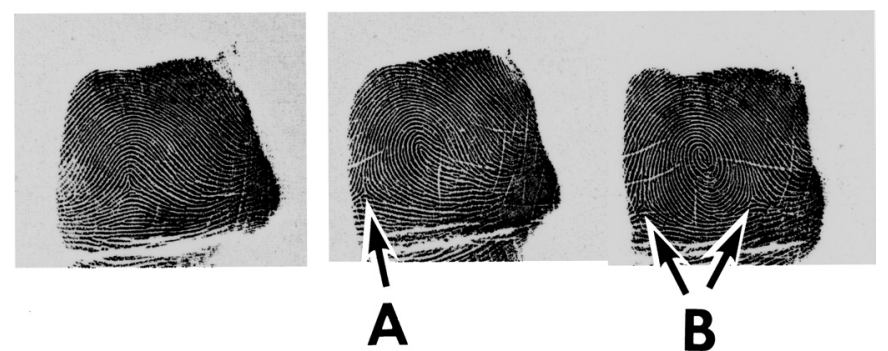

Fig. 1 Figure 1 shows the basic fingerprint types. The arch has no triradius, the loop has a single triradius (arrow A) and opens to one side, and the whorl has two or more triradi (arrow B). Loops open toward the ulnar (U) or radial (R) side of the hand and are designated accordingly.

plantae. The timing of pad appearance and disappearance matches the appearance of the ridge. The ridge begins to appear while the pad swell remains, forming a pattern on the skin, and depending on the degree of curve and distortion, it becomes a whorl or ulnar loop. If a ridge forms after the pad disappears, straight and simple fingerprints like an arch are produced. We suggest that arch frequency particularly increases under the influence of genetic and environmental factors. Conversely, the length of pad retention was longer in the viviparity period of parents of Trisomy 21 children. Based on our result, it seems necessary to consider risk factors that pass through the placenta to the intrauterine environment, as well as other factors affecting fetuses and mothers.

The frequency of arch is linked with E-Trisomy, D1-Trisomy in autosome aberration and Klinefelter's syndrome in sex chromosome aberration. Recently, several articles have been published showing that mental retardation is associated with arch frequency (Stevenson et al., 1997) and that anticonvulsant drugs and embryological development of fingerprint are associated (Bokhari et al., 2002). These articles point out that increase of arches is found in the patients. In these studies, obvious physical anomalies were not found in the parents of Trisomy 21 children with arches. Therefore, arches may influence fetal growth, particularly of the ectoderm, which is related to the development of the central nervous system, and mesoderm, related to the development of the blood vascular system. We suggest that the above procedure is linked to

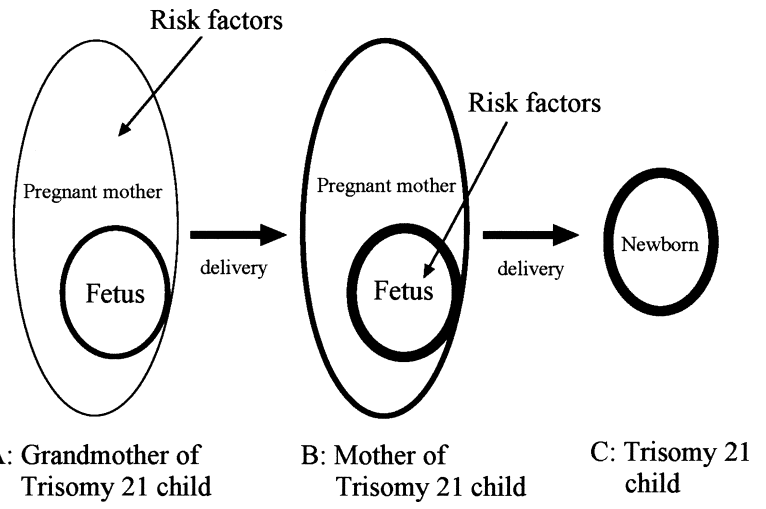

Fig. 2 Diagram of the relationship between risk factors (genetic and environmental) and the frequency of Trisomy 21 children over three generations on the mothers' side.

A: Grandmothers come into contact with various types of risk factors (genetic and environmental), which may affect development of the fingerprints of the fetus. A high frequency of arches is observed in the mother.

B: Remaining risk factors (genetic and environmental) in mothers affect the development of the central nervous and cardiovascular systems in the fetus. Mental retardation and malformation of the heart are observed.

C: Appearance of Trisomy 21 children.

cardiac anomalies and mental retardation, the features of Trisomy 21. Mothers of children with Trisomy 21 showed a significant difference in their frequency of arches. Fathers, 
however, did not. Therefore, we speculated on the relationship between risk factors and the appearance of Trisomy 21 children over three generations on the mothers' side (Fig. 2). In Fig. 2, the fingerprint formations of mothers of Trisomy 21 children are inhibited by various risk factors delivered from grandmothers when mothers are fetuses.

From various reports, it is known that fingerprints are clearly heritable. In order to examine the possibility of bearing Trisomy 21 babies by through an analysis of parental fingerprint types, it is necessary to collect data on the types of fingerprints of parents of Trisomy 21 patients.

We consider that the appearance of particular types of fingerprints will enable us to foresee, to a certain degree, the possibility of parents having Trisomy 21 babies. Our further assumption is that the analysis of parents at the gene level and the investigation of the presence or absence of risk factors would contribute to increased accuracy in predicting the chances of bearing Trisomy 21 babies.

\section{References}

Aihara H, Nishimaru Y, Aihara M, Ono K, Nakamura T, Tokiwa A (1986) Studies on the heredity of the whorl finger pattern (Report 2). Prog Med 6: 3025-3032

Ayme S, Mattei MG, Mattei JF, Aurran Y, Giraud F (1979) Dermatoglyphics in parents of children with Trisomy 21. Clin Genet 15: 78-84

Blank CE (1962) Chromosome abnormality in mongolism. Proc R Soc Med 55: 475-477

Bokhari A, Coull BA, Holmes LB (2002) Effect of prenatal exposure to anticonvulsant drugs on dermal ridge patterns of fingers. Teratol 66: 19-23

Caplan RM (1990) How fingerprints came into use for personal identification. J Am Acad Dernatol 23: 109-114

Carr DH (1962) The chromosome abnormality in mongolism. Can Med Assoc J 87: 490-495

Cummins H, Kennedy RW (1991) Commentatio de examine physiologico organi visus et systematis cutanei. Purkinje's observations (1823) on finger prints and other skin features. 1940. Birth Defects Orig Artic Ser 27: 19-64

Cummins H, Midlo C (1961) Finger prints, palms and soles. [Republished in 1961] Dover Publications, New York

Cushman CJ, Soltan HC (1969) Dermatoglyphics in Klinefelter's syndrome (47, XXY). Hum Hered 19: 641-653

de lzuzquiza Uriszar-Aldaca A, Ascaso Terren C, Ballesta Martinez F (1986) Dermatoglyphic studies in parents of children with Down's syndrome I. Digital Patterns. An Esp Pediatr 25: 87-90

Fujita H (1969) A comparative study on finger patterns of patients with Down's syndrome in Japan. Jpn J Human Genet 14: 198-209

Hojo H (1938) Die Morphologische Verfolgung der Durch verbung Variierten Finger-sowie Palmar- und Plantarabdrucke von Eltern und Kindern. Nagasaki Igaku Zasshi: 2321-2334
Holt SB (1964) The role of dermatoglyphics in medical biology. Med World 101: 112-125

Holt SB, Lindesten J (1964) Dermatoglyphic anomalies in Terner's syndrome. Ann Hum Genet 28: 87-100

Honda T, Ishida M (1990) Dermatoglyphics in couples with recurrent spontaneous abortions. Med Genet Res 11: 117122

Kaplan AR, Zsako S (1970) Biological variables associated with mothers of Children affected with the G1-trisomy syndrome (Down's syndrome). Am J Ment Defic 74: 745-755

Katznelson Bat-Miriam M, Bejerano M, Yakovenko M, Kobyliansky E (1999) Relationship between genetic anomalies of different levels and eviations in dermatoglyphic traits. Part 4: Dermatoglyphic peculiarities of males and females with Down syndrome. Family study. Anthrop Anz Jg 57: 193-255

Kimura S, Kitagawa T (1986) Embryological development of human palmar, plantar, and digital flexion crease. Anat Rec 216: $191-197$

Lambourne GTC (1977) A brief history of fingerprints. J Forens Sci Soc 17: 95-98

Loesch D (1981) Dermatoglyphic studies in the parents of Trisomy 21 children I. Distribution of dermatoglyphic discriminants. Hum Hered 31: 201-207

Okajima M (1975) Dermatoglyphics in medical genetics. Tokyo Igaku 83: 316-329 [In Japanese]

Penrose LS (1969) Dermatoglyphics in Trisomy 17 or 18. J Ment Defic Res 13: 44-59

Pfeiffer RA, Kiera W (1968) Dermatoglyphen bei TurnerSyndrome. Acta Genet Med Gemellol 17: 507-522

Reed T (1981) Dermatoglyphics in medicine- problems and use in suspected chromosome abnormalities. Am J Med Genet 8: 441-429

Rignell A (1985) Significant variations of fingertip dermatoglyphics in Trisomy 21, Down's syndrome. J Ment Defic Res 29: 331-345

Rodewald A, Bär M, Zankl M, Zankl H, Sigrid H, Reicke S, Zang KD (1982) Dermatoglyphic studies in parents of children with Trisomy 21: Detection of hidden mosaicism and its role in genetic counseling. Prog Dermatol Res 84: 371-384

Schauman B, Aiter M (1976) Dermatoglyphics in Medical Disorders. Springer-Verlag, New York, Heidelberg, Berlin

Schmidt R, Dar H, Nitowsky HM (1981) Dermatoglyphic and cytogenetic studies in parents of children with Trisomy 21. Clin Genet 20: 203-210

Shiono H, Kadowaki JI, Tanda H, Hikita M (1977) Dermatoglyphics in Klinefelter's syndrome. J Med Genet 14: $187-189$

Shiono H (1983) Dermatoglyphics and Clinical Applications. Nanzando Company Tokyo, 61-80 [In Japanese]

Shiono H (1986) Dermatoglyphics in medicine. Am J Forensic Path 7: 120-126

Stevenson RE, Häne B, Arena JF, May F, Lawrence L, Lubs 
HA, Schwartz CE (1997) Arch fingerprints, hypotonia and areflexia associated with $\mathrm{X}$ linked mental Retardation. J Med Genet 34: 465-469

Stigler SM (1995) Galton and identification by fingerprints. Genetics 140: 857-860

Than M, Myat KA, Khadijah S, Jamaludin N, Isa MN (1998) Dermatoglyphics of Down's syndrome patients in MalaysA comparative study. Anthrop Anz Jg 56: 351-365

Warkany J, Soukup SW (1963) A chromosomal abnormality in a girl with some features of Down's syndrome (mongolism). J Pediatr 62: 890-894
Received: February 17, 2005

Accepted: October 5, 2005

Correspondence to: Nagahisa Matsuyama, Section of Forensic Medicine Department of International Health Development, Division of Public Health, Graduate School, Tokyo Medical and Dental University, 5-45, Yushima, 1, Bunkyo-ku, Tokyo 113-8519, Japan

Phone: + 81-3-5803-0128

Fax: +81-3-5803-0128

e-mail: e-matsu7@tokyo-med.ac.jp 